\title{
Antibacterial Activity of Ikarugamycin against Intracellular Staphylococcus aureus in Bovine Mammary Epithelial Cells In Vitro Infection Model
}

\author{
Shamsaldeen Ibrahim Saeed ${ }^{1,2, *}$, Erkihun Aklilu ${ }^{1}$, Khalid M. Mohammedsalih ${ }^{2}$, Adewole A. Adekola ${ }^{3}\left({ }^{1}\right.$, \\ Ahmed Elmontaser Mergani ${ }^{4,5}$ (D), Maizan Mohamad ${ }^{1}\left[\right.$ and Nor Fadhilah Kamaruzzaman ${ }^{1, *(1)}$
}

1 Faculty of Veterinary Medicine, University Malaysia Kelantan, Pengkalan Chepa 16100, Kelantan, Malaysia; erkihun@umk.edu.my (E.A.); maizan.m@umk.edu.my (M.M.)

2 Faculty of Veterinary Science, University of Nyala, P.O. Box 155, Nyala 63311, Sudan; marajan83@yahoo.com

3 Pathobiology and Population Science, Royal Veterinary College, Hawkshead Lane, Hatfield AL9 7TA, UK; aadekola18@rvc.ac.uk

4 Department of Microbiology, Faculty of Veterinary Medicine, University of Khartoum, Khartoum North 13314, Sudan; Ahmed.Mohamed@tiho-hannover.de

5 Institute for Biochemistry, University of Veterinary Medicine Hannover, Bünteweg 17, 30559 Hannover, Germany

* Correspondence: shams88ns@gmail.com (S.I.S.); norfadhilah@umk.edu.my (N.F.K.); Tel.: +60-11620-38375 (S.I.S.); +60-9771-7330 (N.F.K.)

\section{check for}

updates

Citation: Saeed, S.I.; Aklilu, E.; Mohammedsalih, K.M.; Adekola,

A.A.; Mergani, A.E.; Mohamad, M.; Kamaruzzaman, N.F. Antibacterial

Activity of Ikarugamycin against Intracellular Staphylococcus aureus in Bovine Mammary Epithelial Cells In Vitro Infection Model. Biology 2021, 10, 958. https://doi.org/10.3390/ biology10100958

Academic Editor: Wito Richter

Received: 23 June 2021

Accepted: 3 August 2021

Published: 25 September 2021

Publisher's Note: MDPI stays neutral with regard to jurisdictional claims in published maps and institutional affiliations.

Copyright: (c) 2021 by the authors. Licensee MDPI, Basel, Switzerland. This article is an open access article distributed under the terms and conditions of the Creative Commons Attribution (CC BY) license (https:// creativecommons.org/licenses/by/ $4.0 /)$.
Simple Summary: Antibiotics are widely used for the treatment and control of bovine mastitis However, the treatment has only been partially effective, as the cure percentage only ranging from 10-30\%. Infection by Staphylococcus aureus (S. aureus) is particularly difficult to treat due to the bacteria's ability to enter and resides inside the host cells. Most antibiotics are ineffective against intracellular bacterial due to the poor penetration into host cells to achieve optimal intracellular bactericidal bioavailability levels. There is therefore, an increasing need to evaluate candidate active substances and develop novel antibiotics effective against intracellular persistence infection. In this study, we examine the potential antibacterial properties of ikarugamycin compound as an alternative drug candidate to be explored for treating persistent bovine mastitis caused by intracellular S. aureus using bovine mammary cell line as an in vitro infection model. We also assessed the potential cytotoxicity effect of ikarugamycin in the infection model. We found that, the ikarugamycin possessed intracellular killing activity against $S$. aureus within the mammary epithelial cell. This finding highlights the potential application of ikarugamycin as a novel antimicrobial for the treatment of $S$. aureus mastitis.

Abstract: Staphylococcus aureus is an ubiquitous and versatile pathogen associated with a wide range of diseases. In animals, this bacterium is one of the causative agents of bovine mastitis, responsible for huge economic losses in the dairy industry. Besides the development of antibiotic resistance, the intracellular survival of $S$. aureus within udder cells has rendered many antibiotics ineffective, leading to therapeutic failure. Our study therefore aims to investigate the in vitro bactericidal activity of ikarugamycin (IKA) against intracellular S. aureus using a bovine mammary epithelial cells (Mac$\mathrm{T}$ cells) infection model and determine the cytotoxic effect. Minimum inhibitory concentration (MIC) was used to determine the antibacterial activity of IKA, and Mac-T cells were infected with S. aureus using gentamicin protection assay. IKA intracellular antibacterial activity assays were used to determine the bactericidal activity of IKA against intracellular $S$. aureus. The cytotoxicity of IKA against Mac-T cells was evaluated using the resazurin assay. We showed that, $S$. aureus is susceptible to IKA with a MIC value of $0.6 \mu \mathrm{g} / \mathrm{mL}$. IKA at $4 \times$ MIC and $8 \times$ MIC have bactericidal activity by reducing 3 and $5 \operatorname{logs}_{10} \mathrm{CFU} / \mathrm{mL}$ of $S$. aureus in the first six-hour of treatment respectively. In addition, IKA demonstrated intracellular killing activity by killing $90 \%$ of intracellular S. aureus at $5 \mu \mathrm{g} / \mathrm{mL}$. This level is comparatively lower than $9.2 \mu \mathrm{g} / \mathrm{mL}$ determined as the half-maximal inhibitory concentration ( $\mathrm{IC}_{50}$ ) of IKA required to kill $50 \%$ of Mac-T cells, highlighting a lower concentration required for bactericidal effect compared to the cytotoxic effect. The study highlighted 
that importance of IKA as a potential antibiotic candidate to be explored for the in vivo efficacy in treating S. aureus mastitis.

Keywords: mastitis; antimicrobial resistance; intracellular bacteria; S. aureus; ikarugamycin

\section{Introduction}

Staphylococcus aureus (S. aureus) is an ubiquitous bacterium and a major pathogenic agents associated with bovine mastitis in lactating dairy cows [1]. Mastitis in the dairy industry is arguably one of the most prevalent disease, leading to substantial economic loss due to the associated reduction in milk production, increased death and culling rates, and increased treatment costs [2,3]. The disease is also associated with profound welfare issues due to the associated morbidity and impact on livestock health [2,3]. Antibiotics administration is considered the most common strategy for treatment and control of bovine mastitis [4]. However, the use of antibiotics has become less effective due to the development of antibiotic resistance against common antibiotics used for mastitis treatment $[4,5]$. In addition, $S$. aureus can invade and survive inside bovine mammary epithelial cells [6], which creates an effective barrier limiting sufficient intracytoplasmic antibiotic bioavailability needed for effective bactericidal effect. This has been associated with poor treatment outcomes in S. aureus mastitis, where the percentage of cure using currently approved antibiotics is approximately $10-30 \%$ [7]. Intracellular S. aureus causing mastitis is less susceptible to common conventional antibacterial agents such as $\beta$-lactams, aminoglycosides, macrolides, and fluoroquinolones due to the inability to penetrate and accumulate in the mammalian cells [8]. The delivery of antibacterial into desired locations in the body is one of the main challenges for successful therapeutics as it needs to cross the host cell membranes either through diffusion or endocytosis [8]. The presence of intracellular $S$. aureus, therefore, provides privileged reservoirs from which re-infection can occur [9], resulting in the long-term disease course and recurrent infection [10]. The intracellular survival of $S$. aureus in mammary epithelial cells has thus been associated with the subclinical bovine mastitis and reinfection in treated dairy cows [11]. The facultative intracellular parasitism and biofilm production of $S$. aureus, therefore, protects them from host immune responses and the effect of antibiotics [12], and this poses huge treatment challenges for the global public and livestock health. Therefore, an urgent need to find novel antimicrobials with capabilities to enter, accumulate and retain within the mammalian cell to achieve therapeutic intracellular level.

Ikarugamycin (IKA) was first isolated as a natural active substance with antibacterial properties from Streptomyces phaeochromogenes subsp. ikaruganensis [13] and belongs to the polycyclic tetramate macrolactams (PTMs) class [13]. Structurally, these classes are similar, containing macrocyclic lactam ring, tetramic acid ring, and a variable set of a carbocyclic rings system. IKA possess 5-6-5 carbocyclic rings, while other PTMs harboring 5-5-6 or 5-5-5 carbocyclic rings [14]. IKA and other PTMs have been reported to possess various biological properties such as antimicrobial [15,16], antiprotozoal [17], antitumor [18], immune regulation [19] as well cytotoxic properties [20]. IKA has also been widely used as an inhibitor for the clathrin-mediated endocytosis uptake pathway in the mammalian cells [20]. However, neither its intracellular antibacterial potency nor its cytotoxic properties towards bovine mammary epithelial cells (Mac-T cell) have been examined. Our present study, therefore, aims to investigate the in vitro antibacterial activities of IKA against intracellular S. aureus in Mac-T cells and the cytotoxicity of the compound.

\section{Materials and Methods}

\subsection{Reagent}

IKA purchased from the TOKU-E company (Batch No: 36531-78-9, Toku-E, Tokyo, Japan) was used for this study. IKA was prepared as a $1 \mathrm{mg} / \mathrm{mL}$ stock solution dissolved 
in dimethyl sulfoxide (DMSO) (Sigma-Aldrich Chemie GmbH, Steinheim, Germany) and stored at $-80^{\circ} \mathrm{C}$. The stock solution was further diluted before use for our experiments in phosphate-buffered saline (PBS) to achieve a final DMSO concentration less than $0.01 \%$ (Figure 1).

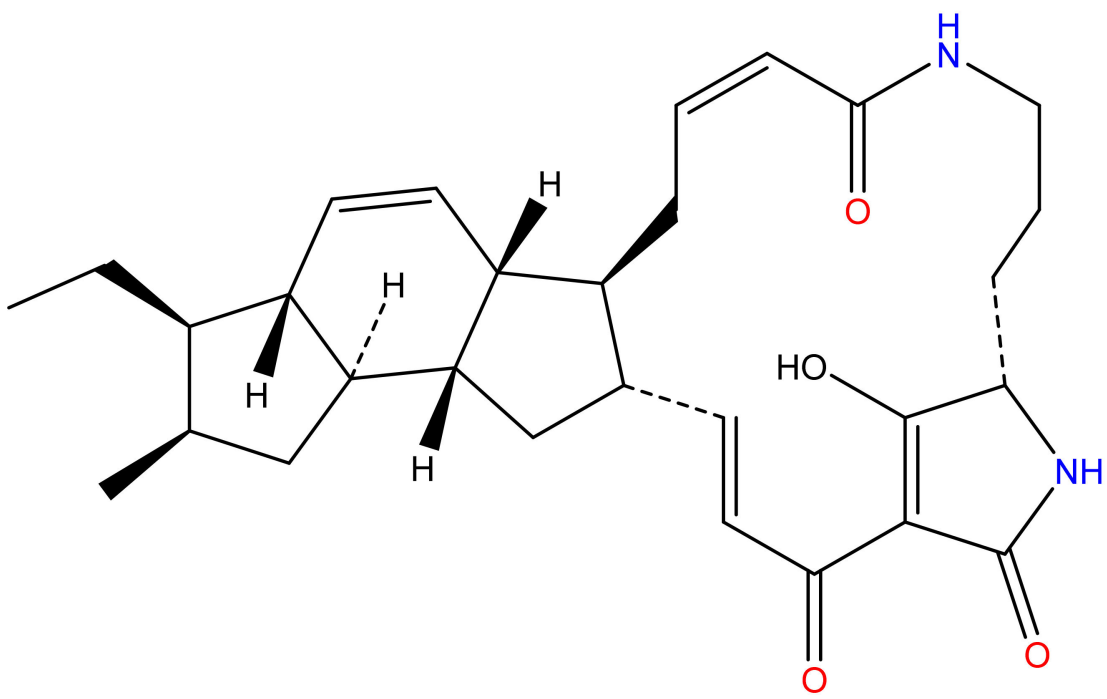

Figure 1. Structure of IKA, which consists of macrolactam ring, tetramic acids, and carbocycles [16]. Image was created using ChemDraw software 14.0 (PerkinElmer, Inc., Akron, OH, USA).

\subsection{Bacterial Strains and Culture Conditions}

Two S. aureus strains (F51B and $15 \mathrm{AL}$ ) were used for this study. S. aureus F51B was isolated from cases of subclinical mastitis on dairy farms on the east coast of Malaysia while the $S$. aureus strain $15 \mathrm{AL}$ strain was obtained from Dr. Shan Goh (Royal Veterinary College, London, UK). All these isolates have previously been confirmed as multi-drug resistance and capable of intracellular localization in mammary epithelial cells. Isolates selected for our were sensitive to chloramphenicol, ciprofloxacin, kanamycin, sulphonamide and gentamicin. The isolates were maintained in $-80^{\circ} \mathrm{C}$ freezer stock. Before the experiment, the bacteria were cultured in Mannitol Salt Agar (MSA) and subsequently grown in Mueller Hinton Broth (MHB) (Oxoid, New Hampshire, UK) at $37^{\circ} \mathrm{C}$ in a shaking incubator at $200 \mathrm{rpm}$ for $24 \mathrm{~h}$.

\subsection{Determination of Minimum Inhibitory Concentrations (MIC) and Minimum Bactericidal Concentration (MBC)}

MIC was performed according to CLSI, 2016. Briefly, the overnight culture of S. aureus was diluted in MHB to achieved $5 \times 10^{5} \mathrm{CFU} / \mathrm{mL}$. The diluted suspension was added into a 96-well microplate containing a range of IKA concentrations in $200 \mu \mathrm{L}$ final volume, followed by incubation at $37^{\circ} \mathrm{C}$ for $18 \mathrm{~h}$. The MIC is defined as the lowest concentration of IKA that inhibited the growth of bacteria. For our study, the MBC was determined as the lowest IKA concentration required to reduce $99.9 \%$ of $\mathrm{CFU} / \mathrm{mL}$ on the agar plates. Control positive and negative were included and each experiment was performed in triplicate [21].

\subsection{Time-Kill Assays}

Time-kill kinetics assays were performed according to (CLSI, 2016) to determine the bactericidal properties of IKA. Briefly, overnight culture of, S. aureus was diluted in tryptic soy broth (TSB). Following that, bacterial was added into tubes containing a designated concentration of IKA $(1 \times \mathrm{MIC}, 4 \times \mathrm{MIC}$, and $8 \times \mathrm{MIC})$ to obtain the final bacterial concentration of $1 \times 10^{5} \mathrm{CFU} / \mathrm{mL}$. The untreated bacteria were included as control. Following that, the tubes were incubated at $37^{\circ} \mathrm{C}$ in a shaking incubator and $100 \mu \mathrm{L}$ of suspension was taken out at various times $(3,6,12,24 \mathrm{~h})$ followed by serial dilution, and plated on nutrient agar. The plates were incubated at $37^{\circ} \mathrm{C}$ for $18 \mathrm{~h}$ followed 
by colony counting to determine the time-killing kinetics. The data were plotted with time against the logarithm of the viable count. Each experiment was performed in triplicate.

\subsection{Bovine Mammary Epithelial Cell Cultures}

Bovine mammary epithelial (MAC-T) cells were obtained from Dr. Amanda Gibson, Royal Veterinary College, London, UK, and used as a host for the in vitro intracellular infection model. The cells were grown in cell culture flask in Dulbecco's modified Eagle's medium (DMEM) (Sigma-Aldrich, St. Louis, MO, USA) supplemented with $10 \%$ fetal bovine serum (FBS) (Sigma-Aldrich, St. Louis, MO, USA), and 5\% penicillin-streptomycin (Sigma-Aldrich, St. Louis, MO, USA). The cells were incubated in $5 \% \mathrm{CO}_{2}$ at $37^{\circ} \mathrm{C}$.

\subsection{Intracellular Invasion Assay}

In vitro infection of MAC-T cells was performed using gentamicin protection assay as previously described [7]. As shown in Figure 2, aliquots of S. aureus diluted to $1 \times 10^{7}$ to $\mathrm{CFU} / \mathrm{mL}$ were co-incubated with host cells for $3 \mathrm{~h}$ for intracellular internalization. Following that, gentamicin $(200 \mathrm{mg} / \mathrm{L})$ was added for another $3 \mathrm{~h}$ to kill extracellular bacteria. Finally, the infected Mac-T cell was lysed using $0.5 \%$ Triton X-100 and the lysed cells were serial diluted and plated on nutrient agar to obtain the $\mathrm{CFU} / \mathrm{mL}$ of intracellular bacteria [7].

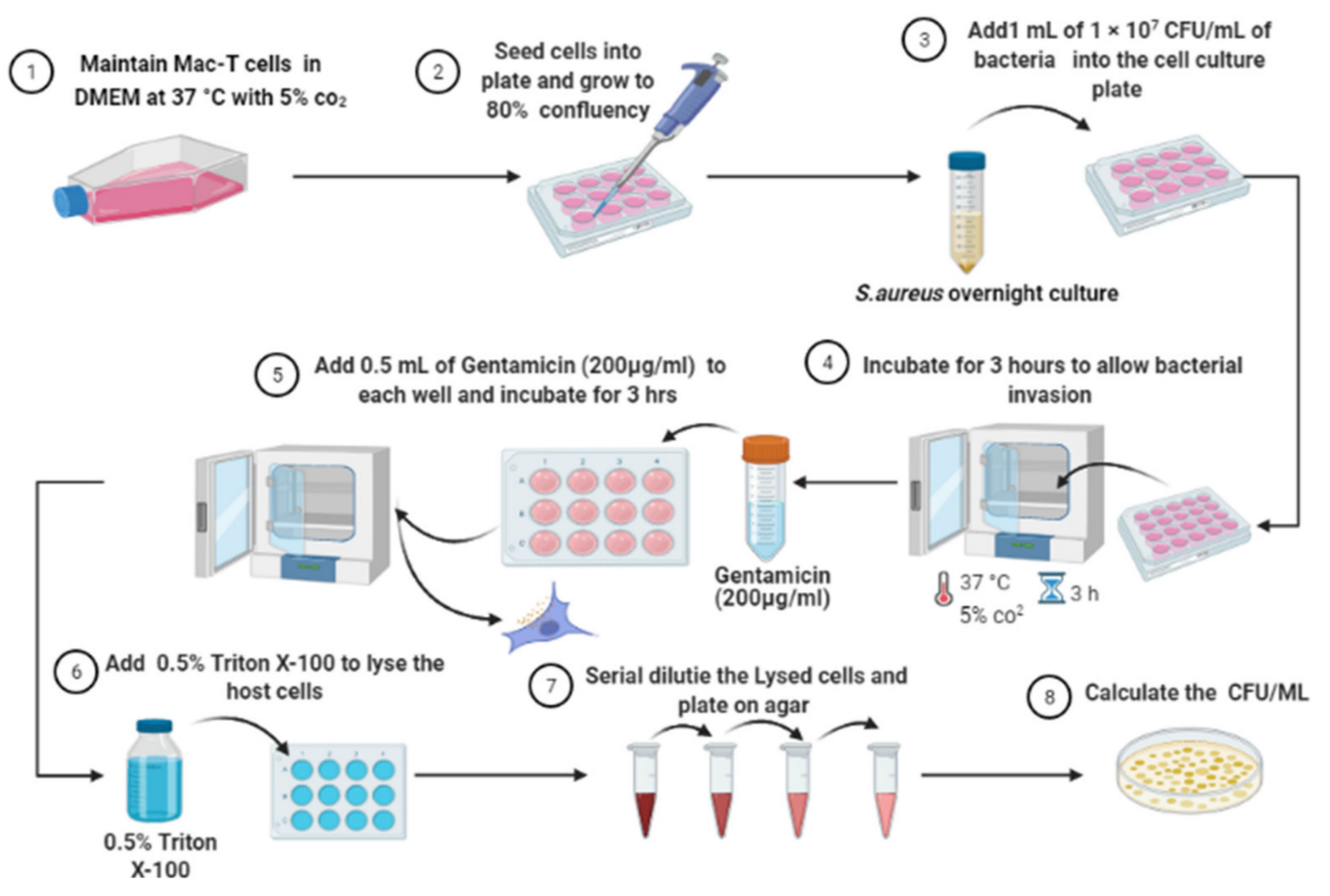

Figure 2. Flowchart of intracellular infection of bovine mammary epithelial cells (Mac-T cells) by S. aureus using a gentamicin protection assay [22]. The image was created using BioRender.com.2021 (Toronto, ON, Canada).

\subsection{Intracellular Antibacterial Activity Assay}

The intracellular antibacterial activities of IKA were performed as previously described [7]. Briefly, MAC-T cells were invaded by S. aureus, followed by incubation with gentamicin to kill the extracellular bacteria. Following gentamicin exposure, host cells were rinsed with PBS. Subsequently, the wells containing infected cells were treated with IKA at $1 \times$ MIC, $4 \times$ MIC, $8 \times$ MIC, and cells without IKA treated were used as control. Plates were incubated for $3 \mathrm{~h}$ to kill the intracellular bacteria. Afterward, IKA was removed, and the cells were lysed after rinsing. Lysed cells were serially diluted and plated on nutrient agar to quantify the remaining survival of bacteria [6,7]. 


\subsection{Cytotoxicity Assay}

The cytotoxicity of IKA toward Mac-T cells was assessed using resazurin assay [23]. Resazurin is a cell-permeable non-fluorescent dye that can be used to monitor the number of viable cells. The blue colored resazurin will be reduced and change into pink color resorufin by the active and viable mammalian cells. Briefly, Mac-T cells $\left(4 \times 10^{4}\right.$ cells /well) were seeded in 96-well plates for $48 \mathrm{~h}$, followed by co-incubation with increasing concentration of IKA up to $10 \mu \mathrm{L} / \mathrm{mL}$ at $37^{\circ} \mathrm{C}$ for $3 \mathrm{~h}$. Control positive and negative were included and each experiments were performed in triplicate. Resazurin dye at $44 \mu \mathrm{M}$ final concentration was added to each well, and then the plate was incubated for $48 \mathrm{~h}$. Finally, the optical density (OD) was measured using POLARstar Omega microplate reader (BMG, Labtech, Germany) at 550 and $630 \mathrm{~nm}$. Survival curves were plotted, and the $\mathrm{IC}_{50}$ (inhibitory concentration 50\%) for IKA was calculated using GraphPad Prism version 8.0 (San Diego, CA, USA).

\subsection{Statistical Analysis}

Data were analyzed by using GraphPad Prism 8 (San Diego, CA, USA). Statistical analysis was performed using a one-way analysis of variance (ANOVA) with Tukey test. Data are presented as means \pm standard deviation (SD). The level of significance was accepted as $p \leq 0.05$. All experiments were performed at least three times.

\section{Results}

3.1. Minimum Inhibitory Concentration and Minimum Bactericidal Concentration of Ikarugammycin

MIC was used to evaluate the antibacterial susceptibility of IKA towards S. aureus. The MIC value for IKA was 0.6 and $5 \mu \mathrm{g} / \mathrm{mL}$ MBC value.

\subsection{Time-Kills Assay}

The results of the time curves assay show that, IKA has bactericidal activity against S. aureus (reducing more than $3 \log _{10}$ ) at 2.5 and $5 \mu \mathrm{g} / \mathrm{mL}$ towards the tested bacteria following $6 \mathrm{~h}$ of exposure (Figure 3 ).

a)

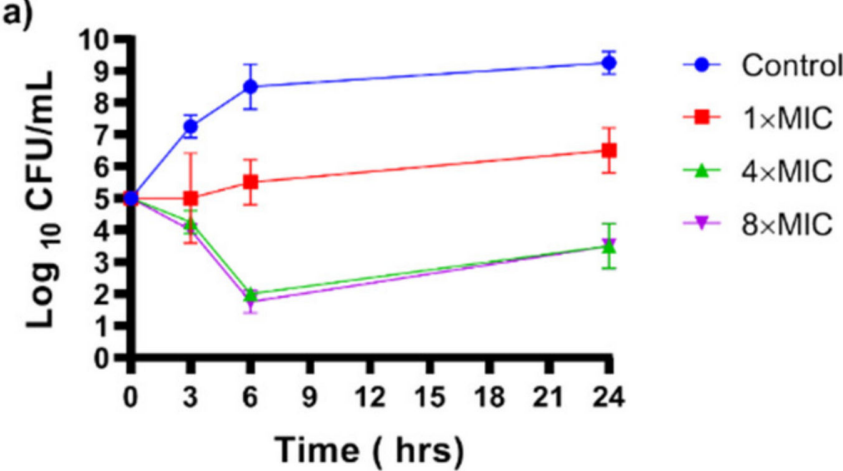

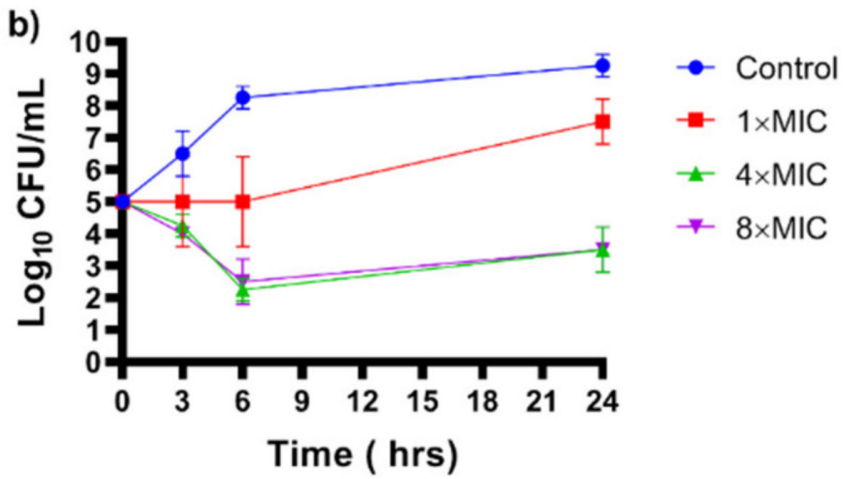

Figure 3. Time-kill curves of S. aureus 15AL (a) and S. aureus F53 B (b) following exposure with IKA for $24 \mathrm{~h}$ at $37^{\circ} \mathrm{C}$. For each time point, an aliquot of bacteria was taken out, serially diluted and plated for colony counting. The experiments were performed in triplicates and each value represents the mean \pm standard deviation of $\log \mathrm{CFU} / \mathrm{mL}$ of bacteria.

\subsection{Intracelluar Infection of Mac-T Cells by S. aureus}

To test the antibacterial activity of IKA against intracellular S. aureus, and in vitro infection modeling of Mac-T cells by $S$. aureus were done using the gentamicin protection assay. Two isolates were confirmed to invade Mac-T cells as indicated by the increase of survival of S. aureus after gentamicin exposure and lysis of Mac-T cells. Lysis of Mac-T cells released approximately $10^{5} \mathrm{CFU} / \mathrm{mL}$ of S. aureus $15 \mathrm{AL}$ and $10^{4} \mathrm{CFU} / \mathrm{mL}$ of F3 3D (Figure 4). 

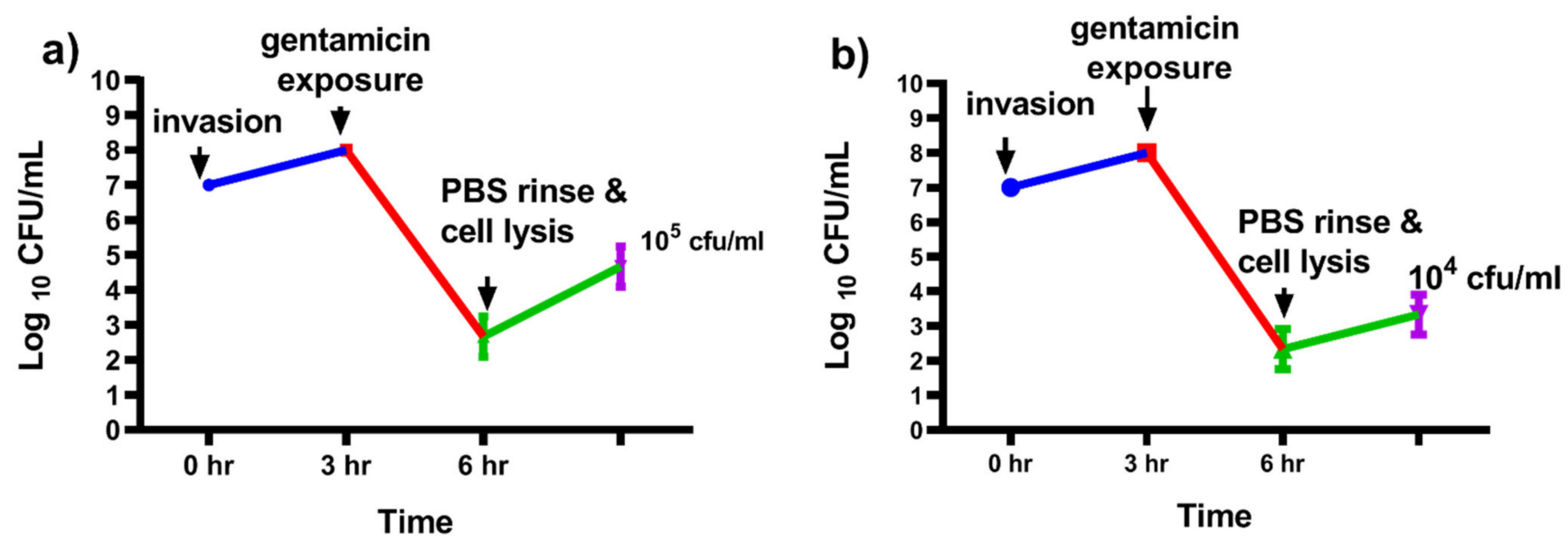

Figure 4. Intracellular survival of S. aureus in Mac-T cells. Following gentamicin exposure, lysis of Mac-T cells released approximately $10^{5} \mathrm{CFU} / \mathrm{mL}$ of $S$. aureus (a) $15 \mathrm{AL}$ and (b) $10^{4} \mathrm{CFU} / \mathrm{mL}$ of $\mathrm{F} 33 \mathrm{D}$. Error bars represent the standard deviation (SD) of triplicates.

\subsection{Bactericidal Activities of Ikarugammycin against Intracellular Staphylococcus aureus}

To determine the antibacterial activity of IKA against intracellular S. aureus, Mac-T cells were infected with $S$. aureus using the gentamicin protection assay. Infected MAC-T cells were treated with different concentrations of IKA $(0.6,2.5$, and $5 \mu \mathrm{g} / \mathrm{mL})$ for $3 \mathrm{~h}$. Following that, IKA was removed, and the cells were lysed to calculate the CFU of surviving intracellular bacteria. The results indicated that, IKA at $5 \mu \mathrm{g} / \mathrm{mL}$ killed between 85 to $90 \%$ of intracellular S. aureus (Figure 5).

a)

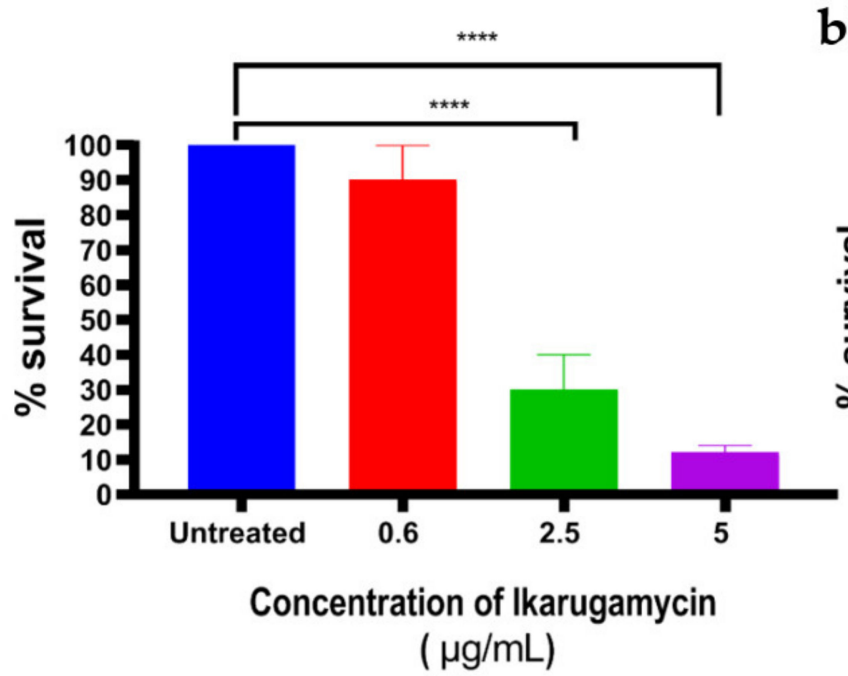

b)

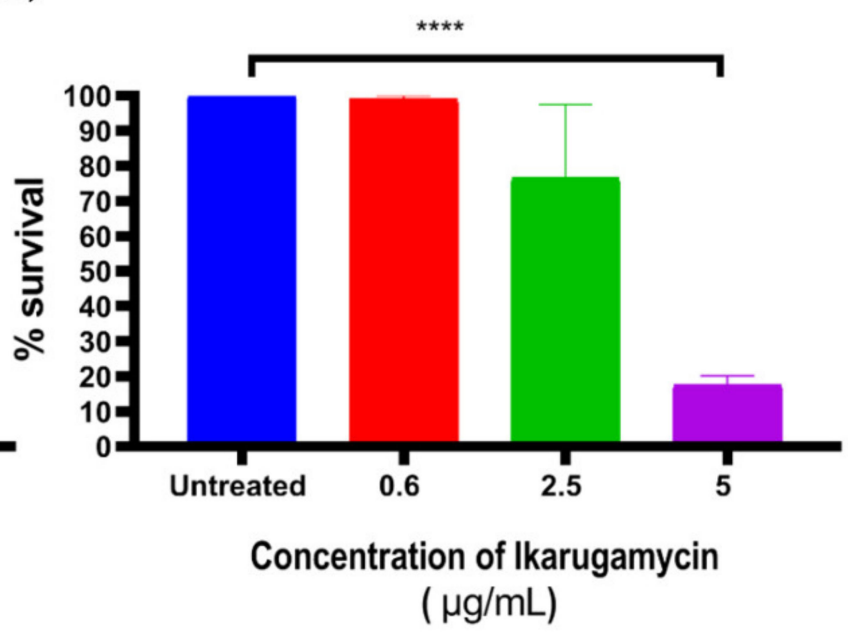

Figure 5. Antibacterial activity of IKA against intracellular S. aureus (a) $15 \mathrm{AL}$ and (b) F53 B. Error bars represent the standard deviation (SD) of triplicates. ${ }^{* * * *} p \leq 0.0001$.

\subsection{Cytotoxicity Assay}

Cytotoxicity test was performed using resazurin reduction assay. Our results highlighted that, the concentration of IKA that inhibited $50 \%$ of MAC-T cells $\left(\mathrm{IC}_{50}\right)$ was $9.2 \mu \mathrm{g} / \mathrm{mL}$; which is higher than the concentration required to kill $90 \%$ of intracellular S. aureus in Mac-T cells Figure 6. 


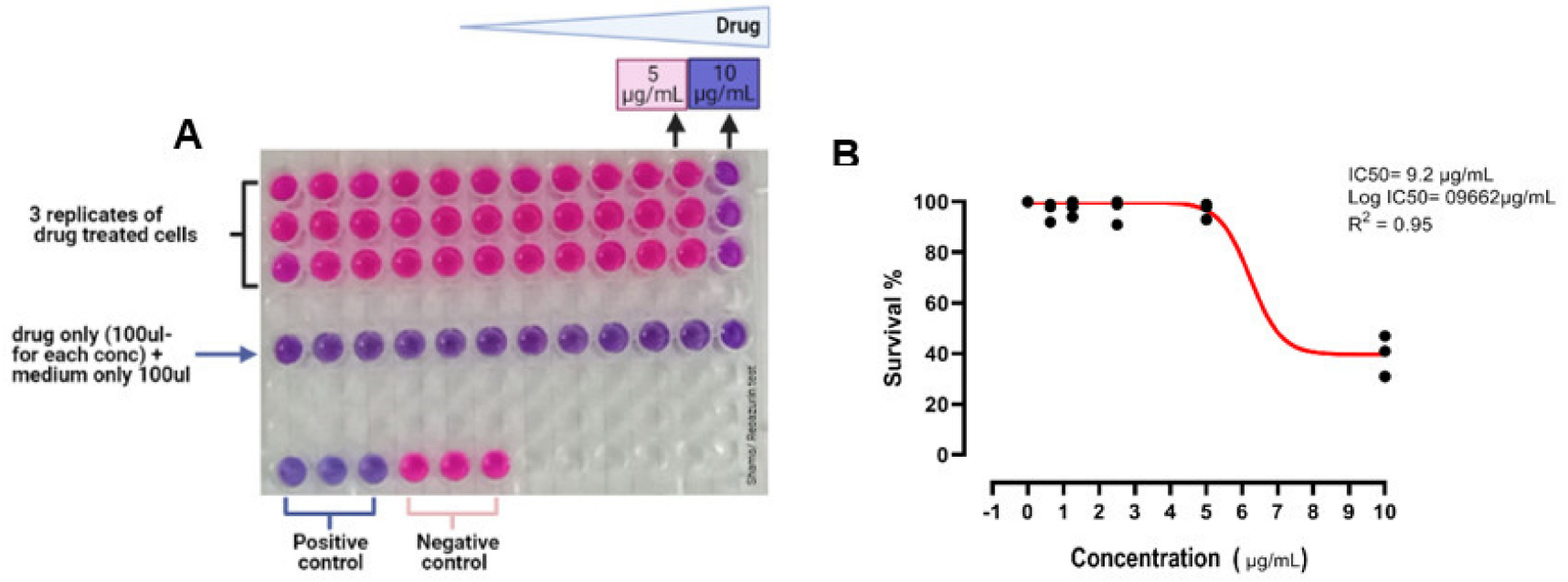

Figure 6. (A) 96-well plate showing resazurin reduction assay after $48 \mathrm{~h}$; (B) dose-response curve showing the IC50 of IKA toward MAC-T cells.

\section{Discussion}

Staphylococcus aureus causing mastitis is a challenging disease in dairy animal and proven to be difficult to combat using conventional antimicrobials due to the development of antimicrobial resistance, and intracellular localization of the bacteria inside the host cell. Here in this study, we demonstrated the antibacterial activities of IKA against intracellular S. aureus and cytotoxic properties toward bovine mammary epithelial cells (Mac-T cells). IKA was effective against the extracellular and intracellular S. aureus and demonstrated low cytotoxicity towards bovine mammary cells.

IKA is a natural product belonging to the polycyclic tetramate macrolactams (PTMs) family [13]. The antibacterial activities of IKA have been hypothesized to be partly due to the interference of the tetramic acid groups with the bacterial proton gradient and membrane potential. This interference could eliminate the cellular proton motive force (PMF) (which plays a crucial role in ATP synthesis and solute transport across the cell) through depletion of the transmembrane proton gradient $(\Delta \mathrm{pH})$ which results to cell death [24]. In addition, macrocyclic lactam ring in IKA could bind to the D-alanyl-Dalanine of bacterial cell wall, thus inhibit the peptidoglycan biosynthesis and disrupt the cell membrane integrity [24,25].

The ability of IKA to kill intracellular activity was probably attributed to several factors. IKA was reported to enter the mammalian cells, and subsequently bind to the DNA [26-28]. Therefore, there are high chances for interaction between the compound and intracellular S. aureus within Mac-T cells. Additionally, IKA is a known compound to demonstrate antitumor activities, attributed to the ability of the compound to induce autophagy of the cells. Cells exposed to the IKA showed increase in the concentration of cytosolic $\mathrm{Ca}^{2+}$, followed by activation CaMKK $\beta$ and AMPK pathway, and ultimately in promotion of autophagy [26]. Autophagy is a cellular processes that target intracellular components including intracellular bacteria $[29,30]$.

Our study also found that the $\mathrm{IC}_{50}$ of IKA (the concentration required to inhibit $50 \%$ of MAC-T cells) was $9.2 \mu \mathrm{g} / \mathrm{mL}$ which was comparatively higher than the concentration required to kill $90 \%$ of intracellular S. aureus in MAC-T cells. This data showed that, IKA is effective as an antimicrobial agent. Several studies have reported the cytotoxic properties of IKA, and this has been explored for its anti-tumor property [20]. No data are, however, available on the cytotoxicity using MAC-T cells and the precise mechanism of toxicity. Several other studies measured IKA toxicity towards the following cell line, HL-60 human promyelocytic leukemia cells [31], pancreatic cancer cells [18], human monocytic cells [19], mouse macrophage 5774 [32]. IKA toxicity levels varied and highly dependent on the time of exposure and dose of the compound [31]. Nevertheless, in our study, Mac-T cells 
appeared to have tolerance towards IKA with cell viability were only affected when cells were exposed to IKA at a concentration higher than the concentration required to kill intracellular S. aureus in the host cells.

\section{Conclusions}

The present study demonstrated that, IKA has antibacterial activity against intracellular S. aureus in in vitro models in Mac-T cells with host cells tolerance of IKA at concentrations higher than the required concentration to kill the intracellular $S$. aureus. This highlights the potential importance of IKA as an alternative antimicrobial candidate to be explored in the treatment of persistent bovine mastitis caused by S. aureus. Further in vivo studies are needed to evaluate IKA potency and toxicity to further understand the potential application of this compound for bovine mastitis.

Author Contributions: S.I.S. and N.F.K. designed the research and wrote the manuscript; S.I.S. performed the experiment; A.A.A., A.E.M. and K.M.M. wrote the manuscript; E.A., M.M., and N.F.K. supervised the work and revised the manuscript. All authors have read and agreed to the published version of the manuscript.

Funding: This research was funded by the following research grant by the Ministry of Higher Education Malaysia, R/FRGS/A06.00/00686A/001/2017/000427.

Institutional Review Board Statement: Not applicable.

Informed Consent Statement: Not applicable.

Data Availability Statement: Not applicable.

Acknowledgments: We thank Nani Izreen Binti Mohd for her support and technical assistance in cell culture work. Also, we thank Amanda Gibson for providing the Mac-T cells. All work was conducted at the Faculty of Veterinary Medicine, Universiti Malaysia Kelantan.

Conflicts of Interest: The authors declare no conflict of interest. The funders had no role in the design of the study; in the collection, analyses, or interpretation of data; in the writing of the manuscript, or in the decision to publish the results.

\section{References}

1. Vasudevan, P.; Kumar, M.; Nair, M.; Annamalai, T.; Venkitanarayanan, K.S. Phenotypic and genotypic characterization of bovine mastitis isolates of Staphylococcus aureus for biofilm formation. Vet. Microbiol. 2003, 92, 179-185. [CrossRef]

2. Wang, J.; Li, H.; Pan, J.; Dong, J.; Zhou, X.; Niu, X.; Deng, X. Oligopeptide targeting sortase a as potential anti-infective therapy for Staphylococcus aureus. Front. Microbiol. 2018, 9, 245. [CrossRef]

3. Li, C.; Liu, Z. A review on nanosystems as an effective approach against infections of Staphylococcus aureus. Int. J. Nanomed. 2018, 13, 7333-7347.

4. Cheng, W.N.; Han, S.G. Bovine mastitis: Risk factors, therapeutic strategies, and alternative treatments. Asian-Australas. J. Anim. Sci. 2020, 33, 1699. [CrossRef]

5. Gomes, F.; Henriques, M. Control of Bovine Mastitis: Old and Recent Therapeutic Approaches. Curr. Microbiol. 2016, 72, 377-382. [CrossRef] [PubMed]

6. Li, L.; Wang, L.; Gao, Y.; Wang, J.; Zhao, X. Effective antimicrobial activity of plectasin-derived antimicrobial peptides against Staphylococcus aureus infection in mammary glands. Front. Microbiol. 2017, 8, 2386. [CrossRef]

7. Kamaruzzaman, N.F.; Chong, S.Q.Y.; Edmondson-Brown, K.M.; Ntow-Boahene, W.; Bardiau, M.; Good, L. Bactericidal and anti-biofilm effects of polyhexamethylene Biguanide in models of intracellular and biofilm of Staphylococcus aureus isolated from bovine mastitis. Front. Microbiol. 2017, 8, 1518. [CrossRef]

8. Wu, X.; Tan, S.; Xing, Y.; Pu, Q.; Wu, M.; Zhao, J.X. Graphene Oxide as an Efficient Antimicrobial Nanomaterial for Eradicating Multi-Drug Resistant Bacteria In Vitro and In Vivo. Colloids Surf. B Biointerfaces 2017, 157, 1-9. [CrossRef]

9. Clement, S.; Vaudaux, P.; Francois, P.; Schrenzel, J.; Huggler, E.; Kampf, S.; Chaponnier, C.; Lew, D.P.; Lacroix, J. Evidence of an Intracellular Reservoir in the Nasal Mucosa of Patients with Recurrent Staphylococcus aureus Rhinosinusitis. J. Infect. Dis. 2005, 192, 1023-1028. [CrossRef] [PubMed]

10. Monack, D.M.; Mueller, A.; Falkow, S. Reviews Persistent Bacterial Infections: The Interface of The Pathogen and The Host Immune System. Nat. Rev. Microbiol. 2004, 2, 747-765. [CrossRef] [PubMed]

11. Fraunholz, M.; Sinha, B. Intracellular Staphylococcus aureus: Live-in and let die. Front. Cell. Infect. Microbiol. 2012, 2, 43. [CrossRef] [PubMed] 
12. Rollin, G.; Tan, X.; Tros, F.; Dupuis, M.; Nassif, X.; Charbit, A.; Coureuil, M. Intracellular survival of Staphylococcus aureus in endothelial cells: A matter of growth or persistence. Front. Microbiol. 2017, 8, 1354. [CrossRef]

13. Zhang, G.; Zhang, W.; Zhang, Q.; Shi, T.; Ma, L.; Zhu, Y.; Li, S.; Zhang, H.; Zhao, Y.-L.; Shi, R.; et al. Mechanistic Insights into Polycycle Formation by Reductive Cyclization in Ikarugamycin Biosynthesis. Angew. Chem. Int. Ed. 2014, 53, 4840-4844. [CrossRef] [PubMed]

14. Cao, S.; Blodgett, J.A.V.; Clardy, J. Targeted Discovery of Polycyclic Tetramate Macrolactams from an Environmental Streptomyces Strain. Org. Lett. 2010, 12, 4652-4654. [CrossRef] [PubMed]

15. Trabelsi, I.; Oves, D.; Gutierrez Magan, B. Isolation, Characterization and Antimicrobial Activities of Actinomycetes Isolated from a Tunisian Saline Wetland. J. Microb. Biochem. Technol. 2016, 8, 465-473. [CrossRef]

16. Lacret, R.; Oves-Costales, D.; Gómez, C.; Díaz, C.; De la Cruz, M.; Pérez-Victoria, I.; Vicente, F.; Genilloud, O.; Reyes, F. New Ikarugamycin Derivatives with Antifungal and Antibacterial Properties from Streptomyces zhaozhouensis. Mar. Drugs 2015, 13, 128-140. [CrossRef] [PubMed]

17. Jomon, K.; Kuroda, Y.; Ajisaka, M.; Sakai, H. A new antibiotic, ikarugamycin. J. Antibiot. 1972, 25, 271-280. [CrossRef]

18. Jiang, S.; Dong, F.; Da, L.; Yang, X.; Wang, X.; Weng, J.; Feng, L.; Zhu, L.; Zhang, Y.; Zhang, Z.; et al. Ikarugamycin inhibits pancreatic cancer cell glycolysis by targeting hexokinase 2. FASEB J. 2020, 34, 3943-3955. [CrossRef]

19. Luo, T.; Fredericksen, B.L.; Hasumi, K.; Endo, A.; Garcia, J.V. Human Immunodeficiency Virus Type 1 Nef-Induced CD4 Cell Surface Downregulation Is Inhibited by Ikarugamycin. J. Virol. 2001, 75, 2488-2492. [CrossRef]

20. Elkin, S.R.; Oswald, N.W.; Reed, D.K.; Mettlen, M.; MacMillan, J.B.; Schmid, S.L. Ikarugamycin: A natural product inhibitor of clathrin-mediated endocytosis. Traffic 2016, 17, 1139-1149. [CrossRef] [PubMed]

21. CLSI. Performance Standards for Antimicrobial Susceptibility Testing; Clinical and Laboratory Standards Institute: Wayne, PA, USA, 2016.

22. Edwards, A.M.; Massey, R.C. Invasion of Human Cells by a Bacterial Pathogen. J. Vis. Exp. 2011, e2693. [CrossRef] [PubMed]

23. Markossian, S.; Sittampalam, G.S.; Grossman, A.; Brimacombe, K.; Arkin, M.; Auld, D.; Austin, C.P.; Baell, J.; Caaveiro, J.M.M.; Chung, T.D.Y.; et al. Assay Guidance Manual; Eli Lilly \& Company and the National Centre for Advancing Translational Sciences: Bethesda, MD, USA, 2021.

24. Lowery, C.A.; Park, J.; Gloeckner, C.; Meijler, M.M.; Mueller, R.S.; Boshoff, H.I.; Ulrich, R.L.; Barry, C.E.; Bartlett, D.H.; Kravchenko, V.V.; et al. Defining the Mode of Action of Tetramic Acid Antibacterials Derived from Pseudomonas aeruginosa Quorum Sensing Signals. J. Am. Chem. Soc. 2009, 131, 14473-14479. [CrossRef] [PubMed]

25. Yu, X.; Sun, D. Macrocyclic Drugs and Synthetic Methodologies toward Macrocycles. Molecules 2013, 18, 6230-6268. [CrossRef]

26. Popescu, R.; Heiss, E.H.; Ferk, F.; Peschel, A.; Knasmueller, S.; Dirsch, V.M.; Krupitza, G.; Kopp, B. Ikarugamycin induces DNA damage, intracellular calcium increase, p38 MAP kinase activation and apoptosis in HL-60 human promyelocytic leukemia cells. Mutat. Res. Fundam. Mol. Mech. Mutagen. 2011, 709, 60-66. [CrossRef] [PubMed]

27. Dhaneesha, M.; Hasin, O.; Sivakumar, K.C.; Ravinesh, R.; Naman, C.B.; Carmeli, S.; Sajeevan, T.P. DNA Binding and Molecular Dynamic Studies of Polycyclic Tetramate Macrolactams (PTM) with Potential Anticancer Activity Isolated from a SpongeAssociated Streptomyces zhaozhouensis subsp. mycale subsp. nov. Mar. Biotechnol. 2019, 21, 124-137. [CrossRef]

28. Minamidate, A.; Onizawa, M.; Saito, C.; Hikichi, R.; Mochimaru, T.; Murakami, M.; Sakuma, C.; Asakawa, T.; Hiraoka, Y.; Oshima, S.; et al. A potent endocytosis inhibitor Ikarugamycin up-regulates TNF production. Biochem. Biophys. Rep. 2021, $27,101065$.

29. Hu, W.; Chan, H.; Lu, L.; Wong, K.T.; Wong, S.H.; Li, M.X.; Xiao, Z.G.; Cho, C.H.; Gin, T.; Chan, M.T.; et al. Autophagy in intracellular bacterial infection. Semin. Cell Dev. Biol. 2020, 101, 41-50. [CrossRef]

30. Dyshlovoy, S.A. Blue-print autophagy in 2020: A critical review. Mar. Drugs 2020, 18, 482. [CrossRef]

31. Malcomson, B.; Wilson, H.; Veglia, E.; Thillaiyampalam, G.; Barsden, R.; Donegan, S.; El Banna, A.; Elborn, J.; Ennis, M.; Kelly, C.; et al. Connectivity mapping (ssCMap) to predict A20-inducing drugs and their antiinflammatory action in cystic fibrosis. Proc. Natl. Acad. Sci. USA 2016, 113, E3725-E3734. [CrossRef]

32. Hasumt, K.; Shinohara, C.; Naganuma, S.; Akira, E.N.D. Inhibition of the uptake of oxidized low-density lipoprotein in macrophage 5774 by the antibiotic ikarugamycin. Eur. J. Biochem. 1992, 846, 841-846. [CrossRef] 